\title{
Does artificial nutrition improve outcome of critical illness? An alternative viewpoint!
}

\author{
Daren K Heyland ${ }^{* 1}$ and Paul E Wischmeyer ${ }^{2}$
}

\begin{abstract}
Recent studies challenge the beneficial role of artificial nutrition provided to critically ill patients and point out the limitations of existing studies in this area. We take a differing view of the existing data and refute many of the arguments put forward by previous authors. We review the mechanistic, observational, and experimental data supporting a role for early enteral nutrition in the critically ill patient. We conclude without question that more, high-quality research is needed to better define the role of artificial nutrition in the critical care setting, but until then early and adequate delivery of enteral nutrition is a legitimate, evidence-based treatment recommendation and we see no evidence-based role for restricting enteral nutrition in critically ill patients. The role of early supplemental parenteral nutrition continues to be defined as new data emerge.
\end{abstract}

When artificial nutrition was first introduced decades ago, it was considered metabolic supportive care for the critically ill, catabolic patient unable to ingest alimentation by mouth. As such, initial evaluation studies were small, single-centered, and focused on nutritional or metabolic outcome parameters. We acknowledge our original studies were weak, but we have come a long way since those days. Now our sample sizes are much larger, studies are more likely to be multicentered, trials are now focused only on critically ill patients (and not elective surgery), and trials are powered for clinically important primary outcomes such as mortality and infection [1]. We agree with Dr Schetz and colleagues that we desperately need more high-quality research in the ICU nutrition field, but we disagree with their interpretation

*Correspondence: dkh2@queensu.ca

'Angada 4, Kingston General Hospital, Department of Medicine, Queens University, Kingston, Ontario, Canada K7L 2V7

Full list of author information is available at the end of the article of the existing evidence about the impact of nutrition in the critically ill patient [2]. In particular, we suggest that the unphysiologic intervention of artificial nutrition applies mostly to parenteral nutrition (PN), particularly high-dose intravenous glucose administration, not to standard enteral nutrition (EN). We do not consider that EN and PN should be considered as equal therapies and their safety and efficacy warrant separate comments.

One derives the truth about the merits of a particular intervention after careful, explicit, and conscientious consideration of all the evidence related to the particular intervention. This includes the tremendous amount of preclinical data that demonstrate numerous positive mechanistic effects of EN, including maintenance of gut integrity, attenuated oxidative stress, reduced systemic inflammation, support of humoral immunity, and enhanced insulin sensitivity, to name a few [3]. However, interestingly Schetz and colleagues argue from a mechanistic point of view that artificial nutrition is harmful because it suppresses autophagy. Autophagy undoubtedly has been known since the 1970 s to be a critical response to starvation [4]. Activation of autophagy in starvation states is thought to be beneficial and key for energetic balance. This activation occurs via cellular protein breakdown leading to recycling of amino acids in lysosomes, which serves to sustain protein synthesis, even in the absence of amino acids coming from the diet, EN, or PN $[4,5]$. These amino acids are then available to be utilized directly (although inefficiently) to generate ATP via entry at different steps of the Krebs cycle. However, as Schetz and colleagues indicate, this is clearly associated with loss of lean muscle mass. This loss of lean body mass significantly contributes to the newly understood epidemic of ICU-acquired weakness [6].

Conversely, absolute gene deletions of key proteins in the autophagy pathway in animal models may also contribute to muscle atrophy [7], although this does not accurately reflect the patient condition where a balance of autophagy and anabolism are probably needed to optimize outcome. Schetz and colleagues report associations of critical illness with impaired autophagy; however, these are only associations and no focused study causally links impaired autophagy to adverse clinical outcomes. A 
recent paper by these authors examined the effect of significant hyperglycemia on autophagy in an animal model of burn injury [8]. This study found that, not surprisingly, hyperglycemia led to suppressed autophagy (as externally induced, uncontrolled hyperglycemia would clearly suppress autophagy due to nutrient excess). They then found that restoration of normoglycemia improved autophagy, probably by reducing toxic nutrient excess. While quite important descriptive science, the clinical relevance of induced and untreated hyperglycemia in modern clinical ICU practice is limited because hyperglycemia to the levels used in these studies (250 to $350 \mathrm{mg} / \mathrm{dl}, 13.9$ to $19.4 \mathrm{mmol} / \mathrm{l}$ ) would never be tolerated clinically. Moreover, as the authors acknowledge, the insulin typically used to induce normoglycemia is a potent inhibitor of autophagy [8].

Interestingly, these authors could not confirm their animal findings in critically ill humans, where no relationship was observed between improved glucose control and increased autophagy in human postmortem patient biopsies [9]. A balanced autophagy response is therefore probably ideal for optimal outcome. Neither nutrient excess (or overfeeding/hyperglycemia) leading to impaired autophagy nor starvation leading to massive breakdown of lean body mass for inefficient energy generation by amino acid stores (or too much autophagy). This is probably best achieved by adequate and balanced nutrition application in critical illness, including sufficient protein to minimize cellular and lean body mass losses. The ideal dose of each macronutrient needed to optimize this balance is unknown and is a basic question needing further research.

Finally, a growing body of recent data has shown that the amino acid glutamine is a potent inducer of autophagy $[10,11]$. Unfortunately, when high doses of glutamine were administered in a pharmacologic fashion very early in severely ill ICU patients with multiorgan failure, mortality was increased [12]! Thus, before any role of autophagy can be used as a justification to feed or not feed in the ICU, a great deal more research is needed to determine whether a real causal role exists for this very important cellular metabolism and immune pathway.

In addition to this mechanistic understanding of the role of nutrition in critical illness and injury, we have large-scale observational studies involving thousands of patients from hundreds of ICUs using statistical techniques adjusting for confounding variables. These large studies consistently describe an association between better nutritional intake and better clinical outcome $[13,14]$. Yes, there are smaller observational studies that have shown an association in the opposite direction but, as we have shown in a recent paper, limitations to their methodological and statistical approach can easily explain away their findings [14].
We also have 16 randomized trials that test the effects of early enteral feeding compared with delayed or no enteral feeding. Since we know that starvation results in death, we find the question of whether to feed illogical and inconsistent with what would be ethically acceptable. More relevant is evaluating the timing of nutritional intervention. Admittedly, there are limitations to these individual trials in terms of their sample size, power, and the nature of the populations studied. However, when meta-analyzed, they suggest an overall treatment effect consistent with a large reduction in mortality (relative risk $=0.72,95 \%$ confidence interval $=0.50$ to 1.04 , $P=0.08$ ) and infection complications (relative risk $=0.81$, 95\% confidence interval $=0.68$ to $0.97, P=0.02$ ) [15] .

Finally, we have randomized trials of feeding protocols showing that increased delivery of nutrition is associated with reduced infection, hospital stay, and mortality $[16,17]$. Taken in their entirety, from the preclinical work to the randomized trials and meta-analysis of randomized trials, we see a consistent signal of benefit in critically ill patients fed enterally early in the course of illness. We should therefore have confidence in our clinical recommendations to feed early with EN given the homogeneity of the positive signals emanating from these different data sources.

Are the results of randomized trials of intentional underfeeding (hypocaloric or trophic feeds vs. full feeds) sufficient to refute the hypothesis that early feeding is beneficial $[18,19]$ ? No, because all of the patients in these studies received early EN - what was being tested was the amount of nutrition that patients received. We do not expect artificial nutrition, either EN or PN, to benefit all patients the same. Only patients at high risk nutritionally speaking are likely to derive an effect of increased delivery of protein and calories on infection, resolution of organ failure, or mortality $[2,20]$. It does not matter how large the study is - if low-risk patients (young, undergoing elective surgery, normal to slightly overweight, with short stays) are randomized to different doses of artificial nutrition, it will be impossible to detect a treatment effect.

The EPaNIC trial succeeded in demonstrating a treatment effect in low-risk patients only because patients in the early group were harmed by high doses of intravenous glucose administered during the first 2 days of ICU stay [21]. There was an early separation of outcomes in this study (greater proportion of patients remaining mechanically ventilated $>2$ days and in the ICU $>3$ days in the early group vs. the late group) that cannot be attributed to PN since it was not started in the early group until day 3. The only difference between these two groups during the first 72 hours of randomization was the large glucose load received by the early group. All differences observed in this study, and subsequent subgroup and 
secondary analyses, are probably due to the harm experienced by patients in the early group (even the subgroup of patients with a contraindication of EN). This inference is stronger than any inferences made by the authors from post-hoc secondary analysis [22]. Furthermore, this unique and extraordinary practice of glucose loading precludes generalizing these data to any other hospital or ICU worldwide. To support this assertion, we cite two recent large-scale trials that contradict EPaNIC findings and demonstrate the safety of early PN in the ICU setting [23,24].

We conclude by returning to our common ground: we need more high-quality, large-scale randomized trials of nutrition interventions in the ICU setting. Where we disagree is that until the results of such studies are available, let us not throw the baby out with the bath water. Early and adequate delivery of EN is a legitimate, evidence-based treatment recommendation and we see no role for restricting EN in critically ill patients. The role of early supplemental PN continues to be defined as new data emerge.

\section{Abbreviations}

EN, enteral nutrition; PN, parenteral nutrition.

\section{Competing interests}

DKH has received research grants and speaker honorarium from Fresenius Kabi, Baxter, Nestle, Abbott, and Biosyn. PEW has received research grants and consulting/speaker honorarium from Baxter, Fresenius, Abbott, Nestle, and Nutricia.

\section{Author details}

'Angada 4, Kingston General Hospital, Department of Medicine, Queens University, Kingston, Ontario, Canada K7L 2V7. ${ }^{2}$ University of Colorado School of Medicine, 12700 E 19th Avenue, Box 8602, RC2 P15-7120, Aurora, CO 80045, USA.

\section{Published: 27 August 2013}

\section{References}

1. Heyland DK, Heyland J, Dhaliwal R, Madden S, Cook D: Randomized trials in critical care nutrition: look how far we've come! (And where do we go from here?) JPEN J Parenter Enter Nutr 2010, 34:697-706.

2. Schetz M, Casaer M, Van den Berghe G: Does artificial nutrition improve outcome of critical illness? Crit Care 2013, 17:302.

3. McClave SA, Heyland DK: The physiologic response and associated clinical benefits from provision of early enteral nutrition. Nutr Clin Pract 2009, 24:305-315.

4. Cuervo AM, Macian F: Autophagy, nutrition and immunology. Mol Aspects Med 2012, 33:2-13.

5. Singh R, Cuervo AM: Autophagy in the cellular energetic balance. Cell Metab 2011, 13:495-504.

6. Griffiths RD, Hall JB: Intensive care unit-acquired weakness [review]. Crit Care Med 2010, 38:779-787.

7. Masiero E, Agatea L, Mammucari C, Blaauw B, Loro E, Komatsu M, Metzger D, Reggiani C, Schiaffino S, Sandri M: Autophagy is required to maintain muscle mass. Cell Metab 2009, 10:507-515.

8. Gunst J, Derese I, Aertgeerts A, Ververs EJ, Wauters A, Van den Berghe G, Vanhorebeek I: Insufficient autophagy contributes to mitochondrial dysfunction, organ failure, and adverse outcome in an animal model of critical illness. Crit Care Med 2013, 41:182-194.
9. Vanhorebeek I, Gunst J, Derde S, Derese I, Boussemaere M, Guiza F, Martinet W, Timmermans JP, D'Hoore A, Wouters PJ, Van den Berghe G: Insufficient activation of autophagy allows cellular damage to accumulate in critically ill patients. J Clin Endocrinol Metab 2011, 96:E633-E645.

10. van der Vos KE, Eliasson P, Proikas-Cezanne T, Vervoort SJ, van Boxtel R, Putker M, van Zutphen IJ, Mauthe M, Zellmer S, Pals C, Verhagen LP, Groot Koerkamp MJ, Braat AK, Dansen TB, Holstege FC, Gebhardt R, Burgering BM, Coffer PJ: Modulation of glutamine metabolism by the PI(3)K-PKB-FOXO network regulates autophagy. Nat Cell Bio/ 2012, 14:829-837.

11. Sakiyama T, Musch MW, Ropeleski MJ, Tsubouchi H, Chang EB: Glutamine increases autophagy under basal and stressed conditions in intestinal epithelial cells. Gastroenterology 2009, 136:924-932.

12. Heyland DK, Muscedere J, Wischmeyer P, Cook D, Jones G, Albert M, Elke G, Berger MM, Day AG; for the Canadian Critical Care Trials Group: A randomized trial of glutamine and antioxidants in critically ill patients. $N$ Engl J Med 2013, 368:1489-1497.

13. Alberda C, Gramlich L, Jones N, Jeejeebhoy K, Day AG, Dhaliwal R, Heyland DK: The relationship between nutritional intake and clinical outcomes in critically ill patients: results of an international multicenter observation study. Intensive Care Med 2009, 35:1728-1737.

14. Heyland DK, Cahill N, Day AG: Optimal amount of calories for critically ill patients: depends on how you slice the cake! Crit Care Med 2011, 39:2619-2626.

15. Early vs. Delayed EN Clinical Practice Guidelines [http://www.criticalcarenutrition.com/index.php?option= com_content\&view=category\&layout=blog\&id=21\&ltemid=10]

16. Martin CM, Doig GS, Heyland DK, Morrison T, Sibbald WJ; Southwestern Ontario Critical Care Research Network: Multicentre, cluster-randomized clinical trial of algorithms for critical-care enteral and parenteral therapy (ACCEPT). CMAJ 2004, 170:197-204.

17. Taylor SJ, Fettes SB, Jewkes C, Nelson RJ: Prospective, randomized, controlled trial to determine the effect of early enhanced enteral nutrition on clinical outcome in mechanically ventilated patients suffering head injury. Crit Care Med 1999, 27:2525-2531.

18. Rice TW, Wheeler AP, Thompson BT, Steingrub J, Hite RD, Moss M, Morris A, Dong N, Rock P: Initial trophic vs full enteral feeding in patients with acute lung injury: the EDEN randomized trial. JAMA 2012, 307:795-803.

19. Arabi YM, Tamim HM, Dhar GS, Al-Dawood A, Al-Sultan M, Sakkijha MH, Kahoul SH, Brits R: Permissive underfeeding and intensive insulin therapy in critically ill patients: a randomized controlled trial. Am J Clin Nutr 2011, 93:569-577.

20. Heyland DK, Dhaliwal R, Jiang X, Day AG: Identifying critically ill patients who benefit the most from nutrition therapy: the development and initial validation of a novel risk assessment tool. Crit Care 2011, 15:R268.

21. Casaer MP, Mesotten D, Hermans G, Wouters PJ, Schetz M, Meyfroidt G, Van Cromphaut S, Ingels C, Meersseman P, Muller J, Vlasselaers D, Debaveye Y, Desmet L, Dubois J, Van Assche A, Vanderheyden S, Wilmer A, Van den Berghe G: Early versus late parenteral nutrition in critically ill adults. N Engl J Med 2011, 365:506-517.

22. Casaer MP, Wilmer A, Hermans G: Role of disease and macronutrient dose in the randomized controlled EPaNIIC trial: a post hoc analysis. Am J Respir Crit Car Med 2013, 187:P247-P255.

23. Heidegger CP, Berger MM, Graf S, Zingg W, Darmon P, Costanza MC, Thibault $\mathrm{R}$, Pichard C: Optimization of energy provision with supplemental parenteral nutrition in critically ill patients: a randomized controlled clinical trial. The Lancet 2012. Published online December 32012 doi:10.1016/S0140-6736(12)61351-8.

24. NHMRC: The effects of early parenteral nutrition compared to standard care on 60 day landmark mortality in the critically ill patient: a level I randomised controlled trial. In Australian New Zealand Clinical Trials Registry. Sydney, NSW: The University of Sydney (Australia); 2010. [http://www.anzctr.org.au/trial_view.aspx?|D=863]

doi:10.1186/cc12701

Cite this article as: Heyland DK, Wischmeyer PE: Does artificial nutrition improve outcome of critical illness? An alternative viewpoint! Critical Care $2013,17: 324$ 